\title{
PENGARUH KEIKUTSERTAAN DALAM PENYULUHAN TENTANG IMUNISASI TERHADAP TINGKAT PENGETAHUAN MASYARAKAT
}

\author{
RIRI SAFITRI ${ }^{1}$, RENI APRINAWATY SIRAIT ${ }^{2}$, NOVITA BR GINTING MUNTHE ${ }^{3}$ \\ Institut Kesehatan Medistra Lubuk Pakam \\ JL. Sudirman No 38 Lubuk pakam \\ e-mail : ririsafitribiologi@gmail.com \\ renisirait1982@gmail.com \\ DOI $10.35451 / \mathrm{jkg} . \mathrm{v} 3 \mathrm{i} 2.564$
}

\begin{abstract}
Although many parents have brought their children to health workers to get immunizations, only a small proportion of parents have knowledge of immunization. So that sometimes there is fear and anxiety after the child is immunized. This is due to the lack of knowledge from parents about immunization. From the background that has been described above, the researchers are interested in examining whether there is an effect of extension on the level of public knowledge in Desa Pasar VI Kualanamu about immunization. The method used in this study is a comparative study with a cross sectional approach. The research sample was taken by accidental sampling technique with a total of 60 respondents. This research was conducted in October 2020 in Pasar VI Kualanamu Village, Beringin District. Data collection was carried out according to health protocols. The instrument used was a questionnaire on respondent characteristics, a questionnaire about immunization knowledge. The data analysis technique used in this study was the Mann-Whitney Test. The results of this study indicate that extension activities are an effective means of conveying information to the public. The level of knowledge of respondents about immunization in the group of extension participants was dominated by respondents who had high scores. Meanwhile, the non-counseling participants were dominated by respondents who had low scores. Based on the results of the analysis using the Mann-Whitney Test to see the effect of counseling on the level of community knowledge in Desa Pasar VI Kualanamu about immunization, it was found that there was a difference in the level of knowledge of respondents about immunization between groups of extension participants and non-participants.
\end{abstract}

Keywords : Immunization education, knowledge level 


\section{PENDAHULUAN}

Imunisasi yaitu salah satu upaya yang dapat dilakukan untuk meminimalisir suatu penyakit dan kematian akibat PD3I (Penyakit yang dapat dicegah dengan imunisasi). Imunitas yang diperoleh melalui imunisasi adalah imunitas aktif. Dengan demikian jika tubuh sesorang terserang oleh patogen maka hanya akan mengalami sakit ringan dan tidak sampai sakit. Penyakit yang Dapat Dicegah dengan Imunisasi (PD3I) diantaranya TBC, Difteri, Tetanus, Hepatitis B, Pertusis, Campak, Polio, radang selaput otak, dan radang paruparu. Dengan imunisasi maka anakanak akan memperoleh perlindungan dari mencegah kecacatan serta kematian (KeMenKes, 2016).

Imunisasi merupakan salah satu cara pencegahan penyakit melalui pemberian imunitas yang diberikan secara teratur sesuai standar yang nantinya mampu memberikan sebuah pertahanan kesehatan dan yang nantinya terjadinya penularan (Palupi, 2011).

Selain berbagai manfaat yang didapatkan, imunisasi juga dapat mengakibatkan gejala saat pelaksanaannya. Menurut (Hadinegoro, 2016) Dalam era globalisasi, imunisasi merupakan upaya pencegahan penyakit infeksi menuju masa depan anak yang lebih sehat. Peningkatan pemberian imunisasi harus diikuti dengan peningkatan efektifitas dan keamanan vaksin. Walaupun demikian, peningkatan penggunaan vaksin akan meningkatkan pula kejadian ikutan pasca imunisasi (KIPI) yang tidak diinginkan. Guna mengetahui apakah KIPI yang terjadi disebabkan oleh imunisasi, maka diperlukan pelaporan pencatatan dari semua reaksi yang timbul setelah pemberian imunisasi. Reaksi KIPI dapat dipantau melalui sistim surveilans yang baik untuk mendapatkan profil keamanan penggunaan vaksin di lapangan. Untuk mengetahui besaran masalah KIPI di Indonesia diperlukan pelaporan dan pencatatan KIPI dan koordinasi antara pengambil keputusan dengan petugas pelaksana di lapangan, guna menentukan sikap dalam mengatasi KIPI yang terjadi. Diharapkan surveilans KIPI dapat membantu program imunisasi, khususnya untuk memperkuat keyakinan masyarakat akan pentingnya imunisasi sebagai upaya pencegahan penyakit yang paling efektif.

Hasil survey yang dilakukan peneliti bahwa meskipun telah banyak para orang tua yang membawa anaknya ke petugas kesehatan untuk mendapatkan imunisasi, namun hanya sebagian kecil dari para orang tua yang memiliki pengetahuan tentang imunisasi. Sehingga terkadang timbul rasa takut dan cemas setelah anaknya diberi imunisasi. Tingkat ketakutan dan kecemasan para orang tua terhadap efek samping dari imunisasi semangkin meningkat di masa pandemi ini, hal tersebut dikarenakan kurangnya pengetahuan dari para orang tua tentang imunisasi.

Menurut (Pramodya \& Nirmala, 2015) Pengetahuan ibu terhadap imunisasi merupakan hal yang sangat penting, agar ibu dapat cepat tanggap dan mengetahui apa yang harus dilakukan jika timbul efek samping pada anaknya. Selanjutnya akan mengubah pola pikir para ibu sehingga ada kesadaran dari para ibu untuk membawa anaknya ke fasilitas kesehatan untuk mendapatkan imunisasi.

Selanjutnya Menurut (Fitriani, 2011) menyatakan bahwa penyuluhan kesehatan merupakan suatu proses kegiatan pemberian informasi tentang hidup sehat untuk mengubah perilaku hidup masyarakat. Penyuluhan kesehatan termasuk salah satu intervensi yang mandiri untuk klien baik 
secara individu, keluarga, kelompok, hingga masyarakat dalam mengatasi masalah kesehatannya.

Dari latar belakang di atas maka peneliti tertarik untuk meneliti adakah pengaruh penyuluhan terhadap tingkat pengetahuan masyarakat di Desa Pasar VI Kualanamu tentang imunisasi pada masa pandemi.

\section{METODE PENELITIAN}

Metode yang digunakan dalam penelitian ini merupakan penelitian komparatif dengan pendekatan cross sectional. Sampel penelitian diambil dengan teknik accidental sampling dengan jumlah 60 responden. Penelitian ini dilaksanakan pada bulan oktober 2020 di Desa Pasar VI Kualanamu Kecamatan Beringin. Pengumpulan data dilakukan sesuai dengan protokol kesehatan. Instrumen yang digunakan berupa kuesioner karakteristik responden, kuesioner pengetahuan tentang imunisasi. Teknik analisis data yang digunakan dalam penelitian ini adalah Mann-Whitney Test.

\section{HASIL PENELITIAN \\ Kegiatan Penyuluhan}

Kegiatan penyuluhan tentang imunisasi, telah dilakukan di desa pasar VI Kualanamu pada bulan September 2020. Kegiatan berjalan dengan baik dan memperoleh respon yang baik. Serta pelaksanaan penyuluhan dilaksanakan sesuai dengan protokol kesehatan.

\section{Karakteristik Responden}

Tabel 1. Distribusi Karakteristik Responden Di Desa pasar VI Kualanamu Kecamatan Beringin $(n=30)$

\begin{tabular}{|c|c|c|}
\hline \multirow[t]{2}{*}{$\begin{array}{l}\text { Karakteristik } \\
\text { Responden }\end{array}$} & $\begin{array}{c}\text { Peserta } \\
\text { Penyuluhan }\end{array}$ & $\begin{array}{c}\text { Bukan } \\
\text { Peserta } \\
\text { Penyuluhan }\end{array}$ \\
\hline & $\%$ & $\%$ \\
\hline
\end{tabular}

\begin{tabular}{|c|c|c|c|c|}
\hline $\begin{array}{l}\text { Jenis } \\
\text { Kelamin }\end{array}$ & & & & \\
\hline Laki-laki & 0 & 0 & 4 & 13.3 \\
\hline $\begin{array}{l}\text { Perempuan } \\
\text { Usia }\end{array}$ & 30 & 100 & 26 & 86.7 \\
\hline $\begin{array}{l}20-40 \text { tahun } \\
>40 \text { tahun }\end{array}$ & $\begin{array}{c}22 \\
8\end{array}$ & $\begin{array}{l}73.3 \\
26.7\end{array}$ & $\begin{array}{l}20 \\
10\end{array}$ & $\begin{array}{l}66.7 \\
33.3\end{array}$ \\
\hline Total & 30 & 100 & 30 & 100 \\
\hline
\end{tabular}

Dari Tabel 1. Diketahui bahwa jenis kelamin responden pada kelompok peserta penyuluhan yaitu perempuan sebanyak 30 responden (100\%) dan laki-laki sebanyak 0 responden $(0 \%)$. Sedangkan pada kelompok bukan peserta penyuluhan sebanyak 26 responden $(86.7 \%)$ untuk jenis kelamin perempuan dan jenis kelamin laki-laki sebanyak 4 responden (13.3\%). Selanjutnya Usia responden pada kelompok peserta penyuluhan yaitu 2040 tahun sebanyak 22 responden dan usia $>40$ tahun sebanyak 8 responden. Sedangkan usia responden pada kelompok bukan peserta penyuluhan yaitu 20-40 tahun sebanyak 20 responden dan usia $>40$ tahun sebanyak 10 responden.

\section{Tingkat Pengetahuan Responden}

Tabel 2. Tingkat Pengetahuan

Responden Tentang Imunisasi

\begin{tabular}{ccccc}
\hline $\begin{array}{c}\text { Tingkat } \\
\text { Pengetahua } \\
\mathrm{n}\end{array}$ & $\begin{array}{c}\text { Peserta } \\
\text { Penyuluha } \\
\mathrm{n}\end{array}$ & $\begin{array}{c}\text { Bukan } \\
\text { Peserta } \\
\text { Penyuluha } \\
\mathrm{n}\end{array}$ \\
\cline { 2 - 5 } Tinggi & $\mathrm{F}$ & $\%$ & $\mathrm{~F}$ & $\%$ \\
Sedang & 7 & 70 & 0 & 0 \\
Rendah & 2 & 6.3 & 12 & 40 \\
Total & 30 & 100 & 30 & 100 \\
\hline
\end{tabular}

Dari tabel 2. Diketahui bahwa tingkat pengetahuan responden pada kelompok peserta penyuluhan yang tergolong tinggi sebanyak 21 responden $(70 \%)$, tergolong sedang sebanyak 7 responden (23.3), tergolong rendah sebanyak 2 responden $(6.7 \%)$. Sedangkan pada kelompok bukan peserta penyuluhan yang tergolong tinggi sebanyak 0 responden $(0 \%)$, tergolong sedang sebanyak 12 responden (40\%), tergolong rendah sebanyak 18 responden $(60 \%)$. 


\begin{tabular}{|c|c|c|c|c|}
\hline \multicolumn{5}{|c|}{$\begin{array}{l}\text { Analisis Perbedaan } \\
\text { Pengetahuan Responde } \\
\text { Imunisasi } \\
\text { Tabel 3. Analisis Perbeda } \\
\text { Pengetahuan Responde } \\
\text { Imunisasi } \\
\text { Mann-Whitney Test }\end{array}$} \\
\hline \begin{tabular}{|l|l} 
\\
\end{tabular} & \multicolumn{4}{|c|}{\begin{tabular}{|r} 
Ranks \\
\end{tabular}} \\
\hline & $\begin{array}{l}\text { Respon } \\
\text { den }\end{array}$ & $\mathrm{N}$ & $\begin{array}{c}\text { Mea } \\
\text { n } \\
\text { Rank }\end{array}$ & $\begin{array}{c}\text { Sum } \\
\text { of } \\
\text { Ran } \\
\text { ks }\end{array}$ \\
\hline \multirow{3}{*}{$\begin{array}{l}\text { Tingk } \\
\text { at } \\
\text { Penge } \\
\text { tahua } \\
\mathrm{n} \\
\text { Tenta } \\
\text { ng } \\
\text { Imuni } \\
\text { sasi }\end{array}$} & $\begin{array}{l}\text { Peserta } \\
\text { Penyulu } \\
\text { han }\end{array}$ & 30 & $\begin{array}{r}43,7 \\
0\end{array}$ & $\begin{array}{r}131 \\
1,00\end{array}$ \\
\hline & $\begin{array}{l}\text { Bukan } \\
\text { Peserta } \\
\text { Penyulu } \\
\text { han }\end{array}$ & 30 & $\begin{array}{r}17,3 \\
0\end{array}$ & $\begin{array}{r}519 \\
00\end{array}$ \\
\hline & Total & 60 & & \\
\hline
\end{tabular}

\begin{tabular}{|l|r|}
\hline \multicolumn{2}{|c|}{ Test Statistics $^{\mathbf{a}}$} \\
\hline & $\begin{array}{c}\text { Tingkat } \\
\text { Pengetahuan } \\
\text { Tentang Imunisasi }\end{array}$ \\
\hline Mann-Whitney U & 54,000 \\
\hline Wilcoxon W & 519,000 \\
\hline Z & $-5,857$ \\
\hline $\begin{array}{l}\text { Asymp. Sig. (2- } \\
\text { tailed) }\end{array}$ \\
\hline \multicolumn{2}{|c|}{ a. Grouping Variable: Responden } \\
\hline
\end{tabular}

Dari Tabel 3. Diketahui berdasarkan output "Test Statistics" dalam uji mannwhitney diatas bahwa nilai Asymp. Sig. (2 -tailed) sebesar 0,000. Nilai tersebut lebih kecil dari $(<)$ nilai probabilitas 0,05 .

\section{PEMBAHASAN}

\section{Kegiatan Penyuluhan}

Kegiatan penyuluhan yang telah yang dilakukan, memperoleh respon yang baik dari peserta penyuluhan imunisasi. Hal tersebut menunjukkan bahwa kegiatan penyuluhan merupakan salah satu sarana yang efektif dalam penyampaian informasi bagi masyarakat. Menurut (Fitriani, 2011) menyatakan bahwa penyuluhan kesehatan merupakan suatu proses kegiatan pemberian informasi tentang hidup sehat untuk mengubah perilaku hidup masyarakat. Penyuluhan kesehatan juga merupakan salah satu bentuk intervensi yang mandiri untuk klien baik secara individu, keluarga, kelompok, maupun masyarakat dalam mengatasi masalah kesehatannya.

\section{Karakteristik Responden}

Karakteristik responden berdasarkan jenis kelamin didominasi oleh jenis kelamin perempuan baik pada kelompok peserta penyuluhan maupun bukan peserta penyuluhan. Selanjutnya berdasarkan usia didominasi oleh usia 20-40 tahun baik pada kelompok peserta penyuluhan maupun kelompok bukan peserta penyuluhan. Hal tersebut menunjukkan bahwa jenis kelamin perempuan dan usia 20-40 tahun memiliki keminatan dan kesadaran yang lebih baik dalam memperoleh informasi tentang imunisasi.

\section{Tingkat Pengetahuan Responden}

Tingkat pengetahuan responden tentang imunisasi pada kelompok peserta penyuluhan didominasi oleh responden yang memiliki nilai tinggi. Sedangkan pada kelompok bukan peserta penyuluhan didominasi oleh responden yang memiliki nilai rendah. Hal tersebut menunjukkan bahwa responden kelompok peserta penyuluhan telah memperoleh informasi tentang imunisasi dari kegiatan penyuluhan yang diikuti sehingga memiliki pengetahuan yang lebih baik. Berdasarkan penelitian (Bomboa et al., 2015) menyatakan bahwasanya adanya peningkatan pengetahuan dan sikap responden sesudah diberikan penyuluhan.

\section{Analisis Perbedaan Tingkat Pengetahuan Responden Tentang Imunisasi}

Nilai Asymp. Sig. (2 -tailed) sebesar 0,000 . Nilai tersebut lebih kecil dari $(<)$ nilai probabilitas 0,05 maka hipoteisis atau "Ha diterima". Sehingga dapat 
dikatakan bahwa ada perbedaan tingkat pengetahuan responden tentang imunisasi pada antara kelompok peserta penyuluhan dengan bukan peserta penyuluhan.

Maka dapat disimpulkan bahwa ada pengaruh penyuluhan tentang imunisasi pada masa pandemi terhadap tingkat pengetahuan masyarakat. Hal tersebut menunjukkan bahwa kegiatan penyuluhan adalah salah satu bentuk kegiatan yang dapat memberikan pengaruh besar terhadap tingkat pengetahuan seseorang serta merupakan sarana yang efektif untuk menyampaikan informasi atau untuk memperoleh informasi yang dibutuhkan. Berdasarkan penelitian (Bomboa et al., 2015) bahwasanya ada pengaruh penyuluhan tentang imunisasi campak terhadap peningkatan pengetahuan dan sikap ibu.

\section{KESIMPULAN}

Kesimpulan dari hasil penelitian ini adalah kegiatan penyuluhan merupakan salah satu sarana yang efektif dalam memberikan informasi kepada masyarakat. Tingkat pengetahuan responden tentang imunisasi pada kelompok peserta penyuluhan paling banyak responden yang memiliki nilai tinggi. Sedangkan pada kelompok bukan peserta penyuluhan paling banyak responden yang memiliki nilai rendah. Berdasarkan hasil analisis menggunakan Mann-Whitney Test untuk melihat pengaruh penyuluhan terhadap tingkat pengetahuan masyarakat di Desa Pasar VI Kualanamu tentang imunisasi pada masa pandemik, diperoleh hasil bahwa ada perbedaan tingkat pengetahuan responden tentang imunisasi antara kelompok peserta penyuluhan dengan bukan peserta penyuluhan..
Bomboa, V. F., Pascoal, M. E., \& Lumy, F. (2015). Pengaruh penyuluhan imunisasi campak terhadap peningkatan pengetahuan dan sikap ibu. JIDAN (Jurnal IImiah Bidan), 3(2), 45-50.

Fitriani, S. (2011). Promosi kesehatan. Graha Ilmu

Hadinegoro, S. R. S. (2016). Kejadian ikutan pasca imunisasi. Sari Pediatri, 2(1), 2-10.

KeMenKes, R. I. (2016). Profil kesehatan Indonesia tahun 2015. Jakarta: Kementerian Kesehatan Republik Indonesia.

Palupi, A. W. (2011). Pengaruh Penyuluhan Imunisasi Terhadap Peningkatan Pengetahuan dan Sikap Ibu Tentang Imunisasi Dasar Lengkap Pada Bayi Sebelum Usia 1 Tahun. UNS (Sebelas Maret University).

Pramodya, R. D., \& Nirmala, S. A. (2015). Pengaruh Penyuluhan Mengenai Imunisasi Terhadap Pengetahuan Dan Sikap Ibu Di Desa Sukarapih Kec. Sukasari. Jurnal Sistem Kesehatan, 1(2).

\section{DAFTAR PUSTAKA}

